\title{
18
}

\section{Comparison of Different Methods in Calculating CSS Percent Capture}

\author{
Weizhe An and Joseph M. Gianvito
}

The Kiski Valley Water Pollution Control Authority (KVWPCA) owns and operates a combined sewer system (CSS) which includes 23 diversion chambers, eight pump stations, $12.6 \mathrm{mi}(20 \mathrm{~km})$ of interceptor sewers, and a wastewater treatment plant (WWTP).

KVWPCA decided to use the United States Environmental Protection Agency (USEPA) Combined Sewer Overflow (CSO) Control Policy presumptive approach Criterion 2 through their long term control plan (LTCP) process. Criterion 2 requires "The elimination or capture for treatment of no less than $85 \%$ by volume of combined sewage collected in the CSS during precipitation events on a system-wide annual average basis." In order to assess the overflow volumes relative to total CSS conveyance on an annual average basis, KVWPCA completed a comprehensive flow monitoring, CSS hydrologichydraulic modeling study, and evaluated several methods to calculate their system percent capture.

These calculation methods can be divided into two categories: the indirect method and the direct method. The indirect method first calculates the percent of flow loss (overflows and flooding) relative to total wet weather flow, and then deducts the percent loss from $100 \%$. The direct method calculates the ratio of flow to the WWTP to the total wet weather flow during wet weather time.

In either method, the determination of dry weather flow and wet weather time is critical. In order to assess the effect of different wet weather flow and time assumptions, different fixed and varied dry weather flow (DWF) thresholds were used. Also, in a large system like KVWPCA, which includes combined and separate sewersheds, the selection of pure combined system flow and mixed system flow also has significant influence on the calculated percent capture estimate.

An, W. and J.M. Gianvito. 2012. "Comparison of Different Methods in Calculating CSS Percent Capture." Journal of Water Management Modeling R245-18. doi: 10.14796/JWMM.R245-18.

(C) CHI 2012 www.chijournal.org ISSN: 2292-6062 (Formerly in On Modeling Urban Water Systems. ISBN: 978-0-9808853-7-8) 
The evaluation demonstrated that the KVWPCA CSS meets the USEPA CSO Control Policy presumptive approach Criterion 2 using any calculation methods. However, it was also determined that the appropriateness of the methods varied: some were considered to be too conservative, while others were too optimistic. Further, several of the methods were most appropriate if used jointly, while others could be used individually. With any of the calculation procedures, the pure combined flow method (i.e. excluding the impact of tributary separate sanitary flows) is recommended.

Although many methods were evaluated, the authors recommended two methods that use a varied DWF threshold, with adjustments to minimize overcounting of wet weather flow (IVC2 and DVC2) as the most reasonable and efficient methods for utilities and engineers in practice.

\subsection{Background}

KVWPCA owns and operates the CSS and WWTP under NPDES (National Pollutant Discharge Elimination System) permit PA0027626 (KLH Engineers, Inc., 2009). KVWPCA provides sewage service to thirteen municipalities located in the Kiskiminetas River Valley and serves approximately 11000 customers.

As part of their LTCP development process, KVWPCA completed a comprehensive flow monitoring and CSS hydrologic-hydraulic modeling study using a SWMM model. The results were presented in the Proceedings of the Annual International Stormwater and Urban Water System Modeling Conference in 2010 (An and Gianvito, 2010). Due to space limitations, the 2010 publication mainly addressed the model development and validation, and only briefly mentioned the application of the percent capture (Capture\%) method.

This chapter will utilize the previous model's typical year simulation and elaborate further on the different Capture $\%$ methods in detail.

\subsection{Methods Overview}

The Capture $\%$ calculation methods use various flow components represented in the system model. The flow components that enter the system are listed in Table 18.1. The flow components that leave the system are listed in Table 18.2.

Table 18.1 The flow components that enter the system.

\begin{tabular}{ll}
\hline \multicolumn{1}{c}{ Entering Flows } & \multicolumn{1}{c}{ Comments } \\
\hline Dry Weather Flow (DWF) & Can be obtained by running DWF simulation \\
RDII & Can be obtained from SWMM report file \\
Runoff & Can be obtained from SWMM report file \\
\hline
\end{tabular}


Table 18.2 The flow components that leave the system.

\begin{tabular}{ll}
\hline \multicolumn{1}{c}{ Leaving Flows } & \multicolumn{1}{c}{ Comments } \\
\hline Regulator Overflows & Can be obtained from SWMM report file \\
Flooding $^{1}$ & Can be obtained from SWMM report file \\
WWTP Outfall & Can be obtained from SWMM report file \\
\hline
\end{tabular}

${ }^{1}$ Flooding is defined as overflows through non-outfall manholes.

The Capture\% calculation methods can be divided into two categories: the indirect method and the direct method. The indirect method first calculates the percentage of flow loss (overflows and flooding) relative to the total wet weather flow, and then deducts the percentage loss from $100 \%$. The direct method calculates the ratio of flow to the WWTP to the total wet weather flow during wet weather time directly.

In either method, defining wet weather flow for the Capture\% evaluation can be difficult given that this key component is not explicitly defined in the CSO Policy presentation of the presumptive approach. Thus in any practical application of the approach it becomes a subjective decision as to when the wet weather flow should end and not be included in the total volume. The longer the recession period included in the calculation, the more favourable the comparison of captured flow to total wet weather flow will be. In any calculation, the wet weather flow period is dependent on an assumption regarding dry weather flow, i.e. the wet weather flow period is assumed to end when the system returns to a dry weather flow condition. In order to assess the effect of different wet weather flow duration assumptions and corresponding volumes, wet weather flow duration was evaluated using different fixed and varied DWF thresholds. With fixed DWF, wet weather conditions are assumed to be occurring whenever WWTP influent flows are larger than a fixed DWF value (a modeler designated single value). With varied DWF, wet weather conditions are assumed to be occurring whenever WWTP influent flows are larger than the diurnally varying DWF time series.

The KVWPCA sewer system is a large sewer system including both combined and separate sewersheds. In many cases, separate sewershed flow enters a combined sewer and is conveyed through one or more diversion structures prior to reaching the interceptor. The Capture\% would be lower if the total wet weather flow calculation excluded separate flow in all of the terms (i.e. it only included combined flow), while it would be higher if the calculation included separate flow. Thus, in either method, the selection of pure combined system flow and mixed system flow also has significant influence on Capture\%. In KVWPCA's case, the Pennsylvania Department of Environmental Protection (PADEP) interpretation of the USEPA CSO Control Policy required that the separate flow be excluded from the Capture\% calculation in mixed flow systems. 
Given the ambiguity inherent in the Capture\% definition and resulting calculation as described above, KVWPCA evaluated the sensitivity of the result to various combinations of assumptions. Table 18.3 presents an overview and abbreviation of the different Capture $\%$ methods evaluated.

Table 18.3 Different Capture\% Methods.

\begin{tabular}{lcccc}
\hline & & Use Flow & Indirect Method & Direct Method \\
\hline \multirow{3}{*}{ Fixed Dry Weather Flow } & Fixed 1 & Mixed & IFM1 & DFM1 \\
& & Pure Combined & IFC1 & DFC1 \\
& Fixed 2 & Mixed & IFM2 & DFM2 \\
& & Pure Combined & IFC2 & DFC2 \\
& Varied 1 & Mixed & IVM1 & DVM1 \\
Varied Dry Weather Flow & & Pure Combined & IVC1 & DVC1 \\
& \multirow{2}{*}{ Varied 2 } & Mixed & IVM2 & DVM2 \\
& & Pure Combined & IVC2 & DVC2 \\
\hline
\end{tabular}

\subsection{Indirect Method}

The indirect method first calculates the percentage of flow loss (overflows and flooding) relative to total wet weather flow, and then deducts the percentage loss from 100\%. It is calculated using Equation 18.1.

$$
\text { Capture } \%=\left[1-(\text { Overflow }+ \text { Flooding }) / W W F_{\text {Total }}\right] \times 100 \%
$$

where:

$$
\begin{aligned}
& \text { Overflow = overflows through all outfalls, obtained from the } \\
& \text { SWMM report file, } \\
& \text { Flooding }=\text { overflows through all non-outfall manholes, obtained } \\
& \text { from the SWMM report file, } \\
& W W F_{\text {Total }}=\text { total wet weather flow during wet weather time, } \\
& \text { calculated using Equation 18.2, and } \\
& W W F_{\text {Total }}=R D I I+R u n o f f+D W F_{A V G, W W T P, W W T}
\end{aligned}
$$

where:

$R D I I=$ flows from the separate system, obtained from the SWMM report file, and

Runoff $=$ flow from the combined system, obtained from the SWMM report file,

$D W F_{A V G, W W T P, W W T}=$ average DWF to the WWTP during wet weather time, calculated by Equation 18.3, and

$\mathrm{DWF}_{\mathrm{AVG}}, \mathrm{WWTP}, \mathrm{WWT}=$ Average $D W F$ Rate $\times$ Wet Weather Time 
Average DWF Rate is calculated by taking the average of the averages of the annual DWF to WWTP, while Wet Weather Time is calculated as the time when the WWTP flow is larger than the WWTP DWF threshold. Thus Wet Weather Time is dependent on the definition of DWF threshold selected.

\subsubsection{Fixed Dry Weather Flow}

As shown in Equations 18.1, 18.2 and 18.3, Overflow, Flooding, RDII and Average DWF Rate can be objectively calculated in the model. The only subjective factor in the indirect method is the choice of the DWF threshold.

The DWF threshold can be taken as the maximum DWF in the year; any flow over $D W F_{\text {Max }}$ is regarded as wet weather flow. This concept is illustrated in Figure 18.1. In the KVWCPA model, $D W F_{\text {Max }}$ was determined to be 2.797 MGD (122 L/s). However, this maximum DWF is conservatively high because it misses many small wet weather flow periods that occur when the associated $D W F$ is lower than $D W F_{\text {Max. }}$.

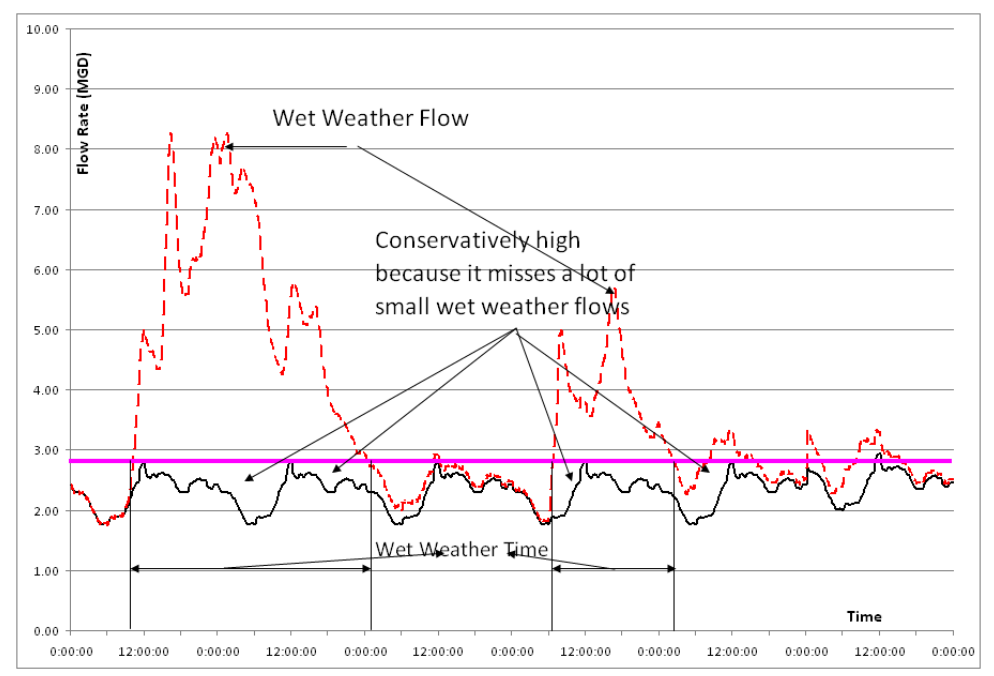

Figure 18.1 Wet weather flow based on maximum fixed DWF.

Using 2.797 MGD (122 L/s) as $D W F_{\text {Max }}$ and Equations 18.1 through 18.3, the key flow components are:

$$
\begin{aligned}
\text { Overflow } & =24.087 \mathrm{MG} \\
\text { Flooding } & =0.000 \mathrm{MG} \\
\text { RDII } & =122.070 \mathrm{MG} \\
\text { Runoff } & =133.804 \mathrm{MG}
\end{aligned}
$$


$D W F_{A V G, W W T P, W W T}=194.889 \mathrm{MG}$

It can be calculated using method IFM1 that Capture\% is 94.66 .

To compensate for the missed wet weather flow time associated with lower flow periods, the DWF threshold can be decreased. For example, if 2.625 MGD $(115 \mathrm{~L} / \mathrm{s})$ is used as $D W F_{M a x}$ and Equations 18.1 through 18.3 are re-applied, the key flow components are:

$$
\begin{aligned}
\text { Overflow } & =24.087 \mathrm{MG} \\
\text { Flooding } & =0.000 \mathrm{MG} \\
\text { RDII } & =122.070 \mathrm{MG} \\
\text { Runoff } & =133.804 \mathrm{MG}
\end{aligned}
$$

$D W F_{A V G, W W T P, W W T}=266.949 \mathrm{MG}$

It can be calculated, using method IFM2, that Capture\% is 95.39 .

It is important to note that the revised $D W F_{\text {Max }}$ of $2.625 \mathrm{MGD}(115 \mathrm{~L} / \mathrm{s})$ was not arbitrarily selected. It was adjusted through multiple calculations to match the calculated Capture\% from the fixed dry weather flow, direct method, as explained further in Section 18.4.1.

\subsubsection{Varied Dry Weather Flow}

Another option to determine the DWF threshold is to utilize the diurnally varying DWF time series from the model. Defined by the modeling team during model calibration, the DWF time series can be obtained by checking Ignore Rainfall/Runoff in the SWMM model, which is shown in Figure 18.2 below.

Using the diurnally varying DWF (not a fixed number) as the threshold, any flow over the DWF is regarded as wet weather flow. This concept is illustrated in Figure 18.3 opposite.

However, due to minor continuity errors in the model and minor model instability, the WWTP influent flow calculated at any given time step in a model simulation can be larger than the corresponding WWTP DWF even under dry weather conditions. Those differences are normally very small, and do not indicate that a rain event has occurred. This is illustrated in Figure 18.4 below.

Using diurnally varying DWF as the threshold, the key flow components are:

$$
\begin{aligned}
\text { Overflow } & =24.087 \mathrm{MG} \\
\text { Flooding } & =0.000 \mathrm{MG} \\
R D I I & =122.070 \mathrm{MG} \\
\text { Runoff } & =133.804 \mathrm{MG}
\end{aligned}
$$

$D W F_{A V G, W W T P, W W T}=10.528 \mathrm{MG}$

It can be calculated using method IVM1 that Capture\% is 97.51 . 


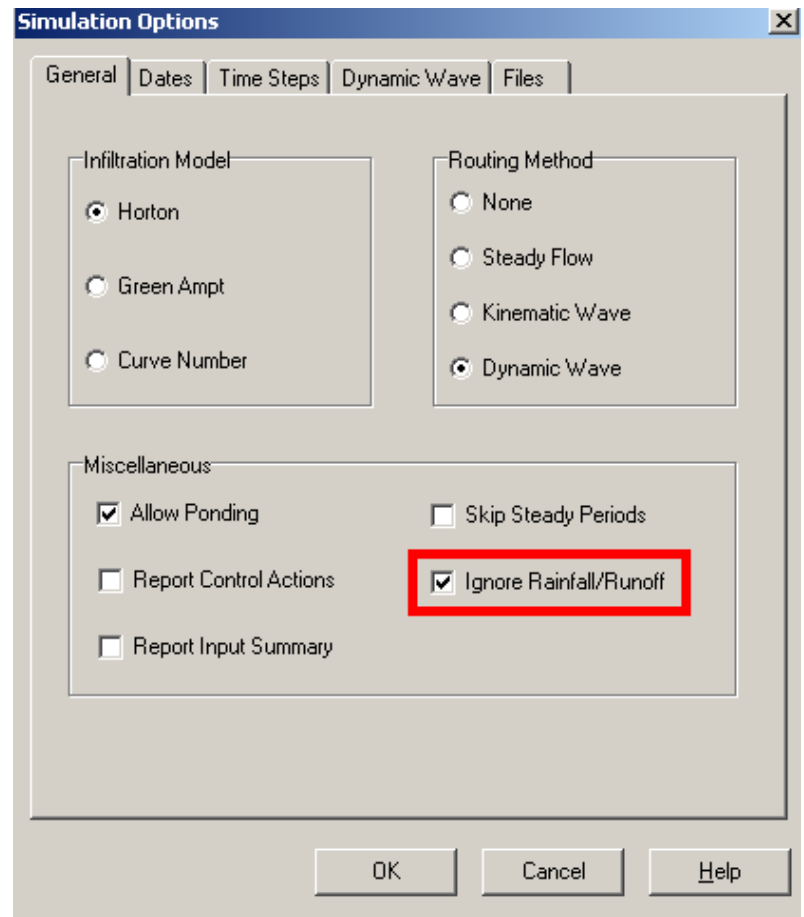

Figure 18.2 Run model ignoring rainfall/runoff.

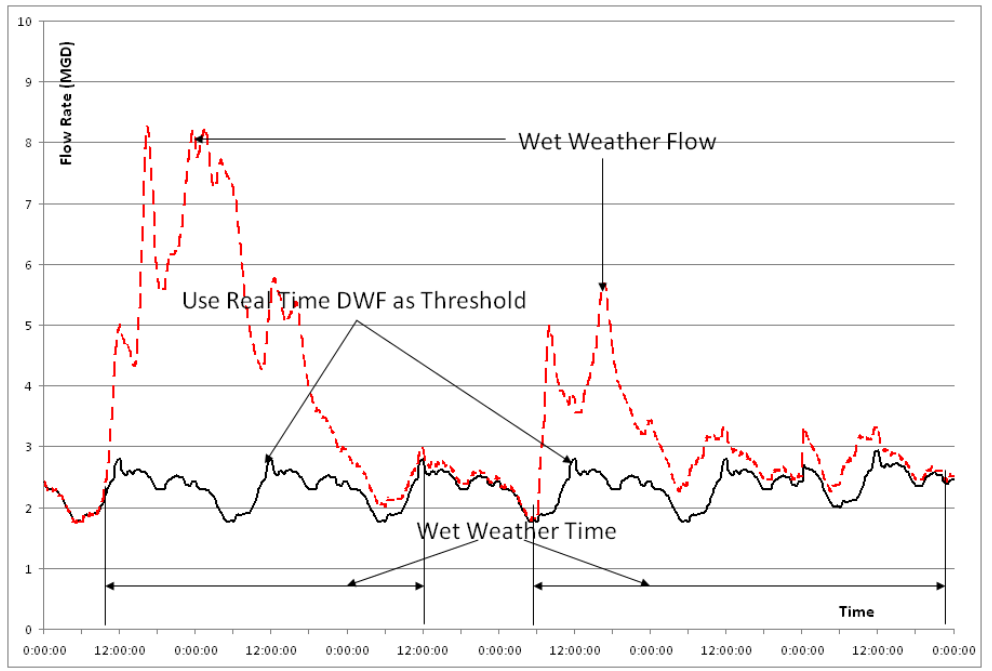

Figure 18.3 Wet weather flow based on diurnally varying DWF. 


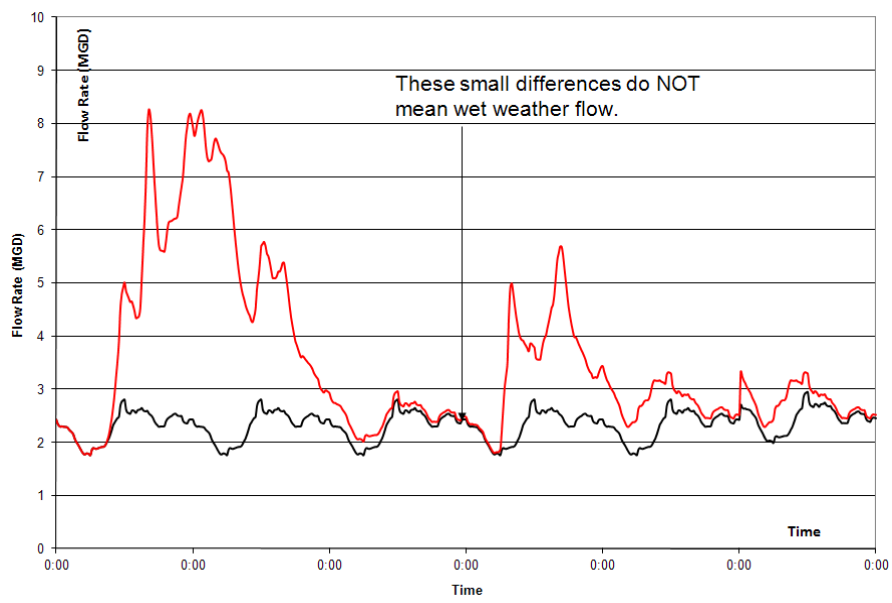

Figure 18.4 Small differences in DWF.

To avoid overcounting the dry weather days as wet weather days, due to the minor modeling instabilities described above, an additional flow component can be added as a safety factor (e.g. 10\% of the minimum DWF). For KVWPCA, this $10 \%$ safety factor resulted in $0.176 \mathrm{MGD}(7.7 \mathrm{~L} / \mathrm{s})$ being added to the diurnally varying DWF. The sum of the original varying DWF plus the safety factor is used as the new DWF threshold. This is illustrated in Figure 18.5.

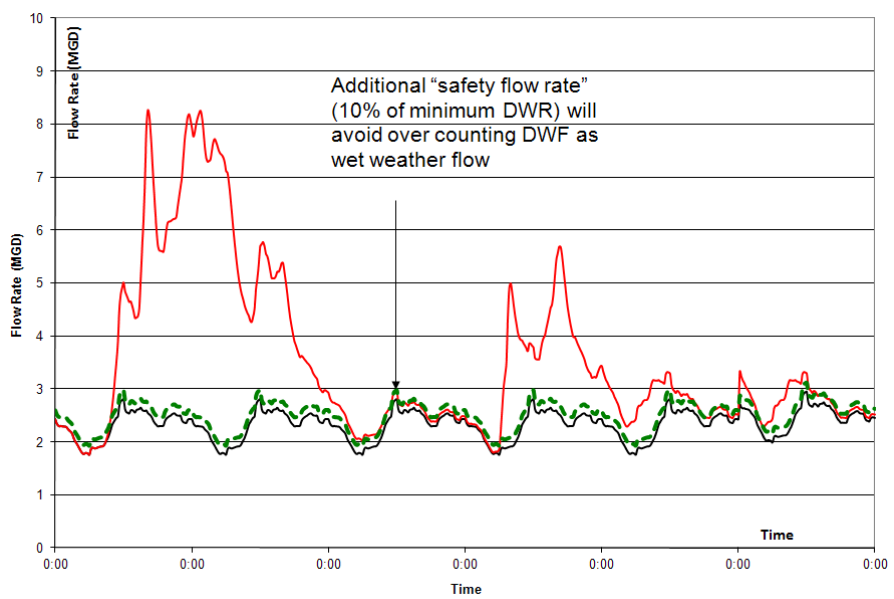

Figure 18.5 Impact of additional safety factor on diurnally varying DWF. 
Using the new diurnally varying DWF as the threshold, the key flow components are:

$$
\begin{aligned}
\text { Overflow } & =24.087 \mathrm{MG} \\
\text { Flooding } & =0.000 \mathrm{MG} \\
R D I I & =122.070 \mathrm{MG} \\
\text { Runoff } & =133.804 \mathrm{MG}
\end{aligned}
$$

$D W F_{A V G, W W T P, W W T}=260.143 \mathrm{MG}$

It can be calculated using method IVM2 that Capture\% is 95.33 .

\subsection{Direct Method}

The direct method calculates the ratio of flow to the WWTP to the total wet weather flow during wet weather time directly. It is calculated using Equation 18.4

$$
\text { Capture } \%=W W F_{W W T P, W W T} / W W F_{\text {Total }} \times 100 \%
$$

where:

$$
\begin{gathered}
W W F_{\text {Total }} \begin{array}{c}
= \\
\text { total wet weather flow during wet weather time, } \\
\text { calculated using Equation } 18.2 \text {, as in section } 3
\end{array} \\
W W F_{W W T P, W W T} \begin{array}{r}
\text { wet weather flow to WWTP during wet weather time, } \\
\text { calculated using Equation } 18.5 \text {, and }
\end{array} \\
W W F_{W W T P, W W T}=W W F_{\text {Pure, } W W T P}+D W F_{W W T P, W W T}
\end{gathered}
$$

where:

$W W F_{\text {Pure }, W W T P}=$ pure wet weather flow to the WWTP, calculated by adding all flows that are larger than DWF, and

$D W F_{W W T P, W W T}=$ dry weather flow to the WWTP during wet weather time, calculated by adding all DWF in wet weather time.

Similar to section 18.3, the wet weather time is a controlling variable in the calculation, and one that varies depending on the definition of DWF threshold.

\subsubsection{Fixed Dry Weather Flow}

As shown in Equations 18.4 and 18.5, the values of $W W T_{P u r e, W W T P}$, $D W F_{W W T P, W W T}$, and $W W F_{\text {Total }}$ depend on the choice of DWF.

Analogous to the approach presented in section 18.3.1, the DWF threshold can be taken as the maximum DWF in the year; any flow over $D W F_{M a x}$ is regarded as wet weather flow. This concept was illustrated in Figure 18.1 above. 
Using 2.797 MGD (122 L/s) as $D W F_{\text {Max }}$ and Equations 18.4 and 18.5, the key flow components are:

$$
\begin{aligned}
W W F_{\text {Pure, } W W T P} & =81.197 \mathrm{MG} \\
D W F_{W W T P, W W T} & =234.398 \mathrm{MG} \\
W W F_{\text {Total }} & =450.763 \mathrm{MG}
\end{aligned}
$$

It can be calculated using method DFM1 that Capture\% is 92.20.

As with the indirect method, the maximum DWF can be considered a conservatively high threshold because it misses many small wet weather flow periods that occur when the associated DWF is lower than typical. Therefore, the DWF threshold can be decreased in order to compensate for the missed wet weather flow time associated with lower flow periods.

From Equations 18.1 and 18.4, it can be seen that

$$
W W F_{W W T P, W W T}+(\text { Overflow }+ \text { Flooding })=W W F_{\text {Total }}
$$

One method to establish an appropriate reduction in the fixed DWF threshold is to compare the results of methods IFC1 and DFC1. Since both method IFC1 and method DFC1 use a fixed DWF, a single DWF value that results in a similar Capture\% value when applying either method can represent a reasonable DWF threshold.

For example, using 2.625 MGD (115 L/s) as $D W F_{\text {Max }}$ and Equations 18.4 and 18.5, the key flow components are:

$$
\begin{aligned}
W W F_{\text {Pure, } W W T P} & =197.978 \mathrm{MG} \\
D W F_{W W T P, W W T} & =266.949 \mathrm{MG} \\
W W F_{\text {Total }} & =522.823 \mathrm{MG}
\end{aligned}
$$

It can be calculated using method DFM2 that Capture\% is 95.51, which approximately equals to the Capture\% in the corresponding calculations in the indirect method in section 18.3 .1 , presented previously as $95.39 \%$. As introduced in Section 18.3.1, the new $D W F_{\text {Max }}$ value of $2.625 \mathrm{MGD}(115 \mathrm{~L} / \mathrm{s})$ is not arbitrarily selected. It was adjusted through multiple calculations until the Capture\% value from method DFC1 (this section) matched the Capture\% value calculated with method IFC1 (section 18.3.1). The new $D W F_{M a x}$ threshold is regarded as reasonable when the Capture\% values generated by these two methods are close.

\subsubsection{Varied Dry Weather Flow}

Similarly to the indirect method, diurnally varying DWF can be employed as the DWF threshold to determine the wet weather flow with the direct method. Using diurnally varying DWF as the threshold, the key flow components are:

$W W F_{\text {Pure, } W W T P}=231.981 \mathrm{MG}$

$D W F_{W W T P, W W T}=710.573 \mathrm{MG}$ 


$$
W W F_{\text {Total }}=966.447 \mathrm{MG}
$$

It can be calculated using method DVM1 that Capture\% is 97.53 .

As explained previously in section 18.3.2, an additional flow component can be added to the diurnally varying DWF as a safety factor in order to avoid having minor modeling instabilities result in over-counting dry weather days as wet weather days. Applying the same 10\% safety factor (0.176 MGD, $7.7 \mathrm{~L} / \mathrm{s})$ to define the new DWF threshold, the key flow components are:

$$
\begin{aligned}
W W F_{\text {Pure, } W W T P} & =206.105 \mathrm{MG} \\
D W F_{W W T P, W W T} & =260.143 \mathrm{MG} \\
W W F_{\text {Total }} & =516.017 \mathrm{MG}
\end{aligned}
$$

It can be calculated using method DVM2 that Capture\% is 95.37 .

\subsection{The Choice of Combined or Mixed Flow}

When KLH presented the above methods and results to PADEP in 2010, the Department argued that Criterion 2 only applies to combined sewer systems, while sanitary sewage should be fully conveyed and treated. Thus, according to PADEP's interpretation, Criterion 2 should be met based on only combined flow volume instead of mixed flow volumes.

From Equations 18.1 through 18.3, it can be seen that the choice of combined flow or mixed flow will affect the average DWF rate and thus affect $D W F_{A V G, W W T P, W W T}$, along with other terms that rely on this estimate. The DWF for combined flow is smaller than the DWF for mixed flow, so the Capture\% value is smaller if combined flow DWF is used. Further, the choice of combined flow or mixed flow will affect the Capture\% value in the direct method in the same manner.

The calculation process for combined-only flow is similar to that used in sections 18.3 and 18.4, with the following modifications:

1. Equation 18.2: RDII (wet weather flow from separate sewer systems) is always zero;

2. Equation 18.3: Average DWF Rate only includes DWF from the CSS;

3. Equation 18.3: Wet Weather Time and associated DWF thresholds only consider DWF from CSS;

4. Equation 18.5: $W W F_{\text {Pure, } W W T P}$ only considers runoff (wet weather flow from CSS); and

5. Equation 18.5: $D W F_{W W T P}, W W T$ only considers DWF from the CSS.

All calculations presented in sections 18.3 and 18.4 use mixed flow to determine DWF and associated estimates. In order to assess the impact of PADEP's interpretation of Criterion 2, the Capture\% values were recalculated 
using only combined flow. A model can be used to simulate only combined flow by assigning all separate RDII areas and all separate sewershed DWF loadings to zero, as shown in Figure 18.6.

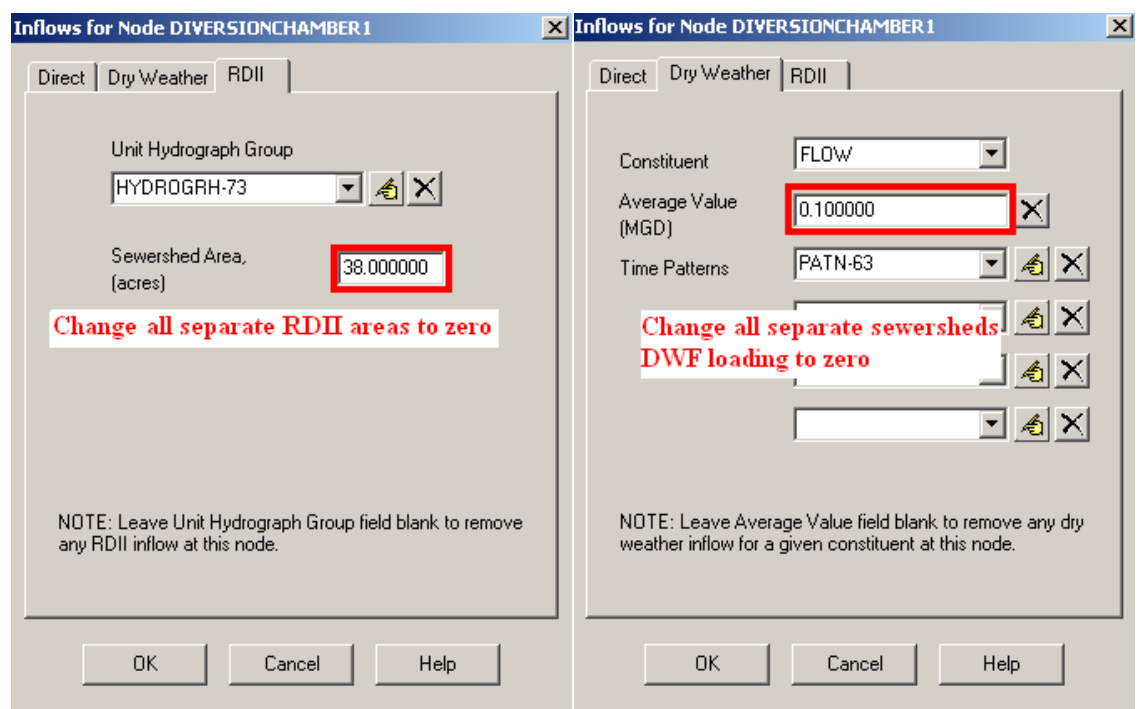

Figure 18.6 Model with combined flow only.

It was determined that the maximum DWF and average DWF from the combined sewersheds are 1.5129 MGD (66 L/s) and 1.2877 MGD (56 L/s) respectively. The calculation results are listed in Table 18.4 in section 18.6 below.

The calculation details for mixed flow were shown in sections 18.3 and 18.4. Due to space limitations, calculation details for pure combined flow will not be presented, but are identical in concept to the mixed flow details presented previously.

\subsection{Percent Capture Results for Different Methods}

All of the calculations presented above can be performed using a spreadsheet, without complicated programming or special software.

A summary of the Capture\% results for all methods is presented in Table 18.4 , along with comparative comments on each set of results. 
Table 18.4 Capture\% results for different methods.

\begin{tabular}{|c|c|c|c|c|c|}
\hline & & Use Flow & $\begin{array}{c}\text { Indirect } \\
\text { Method (\%) }\end{array}$ & $\begin{array}{c}\text { Direct } \\
\text { Method (\%) }\end{array}$ & Comments \\
\hline \multirow{4}{*}{$\begin{array}{l}\text { Fixed Dry } \\
\text { Weather } \\
\text { Flow }\end{array}$} & \multirow[t]{2}{*}{ Fixed $1^{1}$} & Mixed & 94.66 & 92.20 & \multirow{2}{*}{ Too conservative } \\
\hline & & Pure Combined & 90.19 & 88.74 & \\
\hline & \multirow[t]{2}{*}{ Fixed $2^{1}$} & Mixed & 95.39 & 95.51 & $\begin{array}{l}\text { Reasonable by match- } \\
\text { ing indirect and direct } \\
\text { method results }\end{array}$ \\
\hline & & Pure Combined & 90.99 & 90.97 & $\begin{array}{l}\text { Reasonable by match- } \\
\text { ing indirect and direct } \\
\text { method results }\end{array}$ \\
\hline \multirow{4}{*}{$\begin{array}{l}\text { Varied Dry } \\
\text { Weather } \\
\text { Flow }\end{array}$} & \multirow[t]{2}{*}{ Varied $1^{1}$} & Mixed & 97.51 & 97.53 & \multirow{2}{*}{ Too optimistic } \\
\hline & & Pure Combined & 95.54 & 95.69 & \\
\hline & \multirow[t]{2}{*}{ Varied $2^{1}$} & Mixed & 95.33 & 95.37 & $\begin{array}{l}\text { Reasonable by either } \\
\text { one method }\end{array}$ \\
\hline & & Pure Combined & 90.88 & 91.19 & $\begin{array}{l}\text { Reasonable by either } \\
\text { one method }\end{array}$ \\
\hline
\end{tabular}

${ }^{1}$ The 1 and 2 designations refer to DWF thresholds with and without adjustments. For example, Fixed 1 refers to use of the annual maximum DWF value without adjustment as the threshold, while Fixed 2 refers to use of a reduced DWF value as the threshold (to avoid under-counting wet weather flow periods). Varied 1 refers to use of the diurnally varying DWF value without adjustment as the threshold, while Varied 2 refers to use of the increased diurnally varying DWF value as the threshold (to avoid over-counting wet weather flow periods).

\subsection{Conclusions}

From the analysis presented above, it can be seen that:

the pure combined flow method is more conservative (i.e. lower Capture\%) than the mixed flow method for corresponding submethods;

- the fixed dry weather flow method without DWF decrease is more conservative than the varied dry weather flow method without DWF increase;

- the fixed dry weather flow method without DWF decrease is more conservative than the fixed dry weather flow with DWF decrease;

- the varied dry weather flow method without DWF increase is less conservative than the varied dry weather flow method with DWF increase; and

- the fixed dry weather flow with DWF decrease and the varied dry weather flow with DWF increase are hard to compare due to the amount of DWF that they decrease or increase.

Without a DWF decrease, methods IFC1, IFM1, DFC1 and DFM1 will always miss periods with small wet weather flows. As a result, these methods are considered too conservative, and the Capture\% value calculated with these methods can be unrealistically low. 
Without a DWF increase, methods IVC1, IVM1, DVC1 and DVM1 will always over-count a subset of dry weather days as wet weather days. This overcounting of wet weather flow makes these two methods too optimistic, and the Capture\% value calculated using these methods may be unrealistically high.

In the varied DWF method, the Capture\% values calculated by the direct and indirect methods for each sub-method are always close. This consistency in results obtained from using two different calculations helps to validate each of these methods as reliable. It also validates Equation 18.6.

In the fixed DWF method group 2 (with reduced DWF threshold), the Capture $\%$ value calculated by the direct and indirect methods for each sub-method are close, but these results were generated by adjusting $D W F_{M a x}$ to match the direct Capture $\%$ with the indirect Capture $\%$. The results of IFM2 and DFM2 are not only close to each other, but also close to the results of using varied DWF, i.e. IVM2 and DVM2. This consistency across four methods supports their use as reasonable and reliable. The same conclusion can be reached for the analogous pure combined methods; the results of IFC2 and DFC2 are not only close to each other, but also close to the results of IVC2 and DVC2. Since the fixed DWF method requires multiple adjustments to $D W F_{M a x}$ in order to match results between the direct and indirect methods, the varied DWF method is considered more efficient.

PADEP argued that Criterion 2 of the CSO policy should be met based only on combined flow instead of mixed flow. KLH does not disagree with this statement. However, since the whole KVWPCA system is a combined sewer system, counting both combined flow and sanitary flow as combined flow should also be acceptable under the CSO policy. For those municipalities who meet $85 \%$ capture in a pure combined flow method, the pure combined flow method is recommended because it is more conservative and more persuasive. For those municipalities who do not meet the $85 \%$ capture criterion with the pure combined flow method, the mixed flow method can also be applied. However, the regulatory agency may or may not approve this method.

In conclusion, any fixed DWF method that does not incorporate an adjustment to the DWF threshold (methods IFM1, DFM1, IFC1 and DFC1) are too conservative to use. Further, any variable DWF method that does not adjust the threshold (methods IVM1, DVM1, IVC1 and DVC1) is too optimistic to use. With DWF adjustments, fixed methods IFM2 and DFM2 are reasonable if they are used jointly. Methods IFC2 and DFC2 are also reasonable if they are used jointly. With adjustments to variable DWF, methods IVM2 and DVM2 are reasonable whether they are used separately or jointly, with a similar conclusion for methods IVC2 and DVC2 when using pure combined flow. In any calculation procedure, the pure combined flow method is recommended. 


\section{References}

An, W. and J.M. Gianvito. 2010. "Kiski Valley WPCA Combined Sewer System Long Term Model Study." Journal of Water Management Modeling R241-17. doi: 10.14796/JWMM.R241-17.

KLH Engineers, Inc. (2009). Kiski Valley Water Pollution Control Authority Combined Sewer System Flow Monitoring and Modeling Study.

\section{Background Sources}

Chow, V. T., Maidment, D. R., and Mays, L. W. (1988). Applied hydrology, McGrawHill Book Company, New York.

USEPA. (1995a). Combined Sewer Overflows - Guidance for Long Term Control Plan.

USEPA. (1995b). Combined Sewer Overflows - Guidance for Monitoring and Modeling.

USEPA. (2001). Report to Congress - Implementation and Enforcement of the Combined Sewer Overflow Control Policy.

USEPA. (2004). Report to Congress - Impacts and Control of CSOs and SSOs.

USEPA. (2008). Review of Sewer Design Criteria and RDII Prediction Methods.

USEPA. (2009). SWMM 5 Users Manual. 
